\title{
INVESTIGANDO PARÂMETROS DE LEGENDAS PARA SURDOS E ENSURDECIDOS NO BRASIL ${ }^{1}$
}

\section{Vera Lúcia Santiago Araújo e Ana Katarinna Pessoa do Nascimento}

\section{Introdução}

Pesquisadores da Universidade Estadual do Ceará (UECE) vêm investigando a legendagem para surdos e ensurdecidos (LSE) por quase dez anos. O principal objetivo é encontrar parâmetros de LSE que atendam às necessidades dos surdos brasileiros. Três estudos (Franco \& Araújo, 2003 (estudo 1); Araújo, 2004a e 2004b, 2007 (estudo 2) e 2008(estudo 3)) foram desenvolvidos até agora na cidade de Fortaleza. Os resultados sugeriram que os padrões atuais exibidos pelos canais de televisão do Brasil precisam de ajustes e que a condensação e a edição são elementos chave para permitir que os espectadores surdos possam assistir confortavelmente a um programa legendado.

Este artigo tem como objetivo apresentar os primeiros resultados de uma pesquisa exploratória em andamento que investiga a recepção dos parâmetros propostos por um grupo de surdos de Fortaleza expostos a diferentes parâmetros de LSE por oito meses. Os parâmetros escolhidos estão sendo testados por um total de 50 participantes pertencentes a dois estados de cada região do Brasil: Norte (Roraima e Amazonas); Sul (Santa Catarina e Paraná); Sudeste (Rio de Janeiro e Minas Gerais); Nordeste (Ceará e Bahia) e Centro-Oeste (Brasília e Goiás).

Este artigo está dividido em cinco partes. A primeira mostra a atual situação da LSE no Brasil. A segunda apresenta uma pequena revisão dos estudos em LSE realizados na UECE. A terceira apresenta a metodologia utilizada. A quarta discute os primeiros resultados de Fortaleza e Salvador, duas cidades do nordeste brasileiro. Finalmente, na última parte, apontam-se as primeiras conclusões e algumas sugestões para futuras pesquisas.

\section{A LSE no Brasil}

As legendas para ouvintes e aquelas produzidas para surdos e ensurdecidos parecem ser vistas de forma diferente pelos produtores audiovisuais brasileiros e

\footnotetext{
${ }^{1}$ Trabalho apresentado no IV Media For All: Taking Stock, realizado em Londres de 29 de junho a $1^{\circ}$ de julho de 2011.
} 
também pelo governo, já que a produção dos dois tipos de legendas é diferente. A primeira é considerada uma atividade de tradução e segue as normas descritas pelos pesquisadores da área de tradução audiovisual (TAV) (D'Ydewalle et al. 1987; Ivarsson \& Carol, 1998; Díaz Cintas \& Remael, 2007; Neves, 2007). A segunda é vista como uma transcrição da fala e não como tradução. A portaria 310 define a LSE como "transcrição em português dos diálogos, efeitos sonoros e outras informações que não poderiam ser percebidas ou entendidas pelos deficientes auditivos".

As legendas para ouvintes são feitas com o uso de softwares que permitem a marcação (o início e o final de cada legenda), tradução, revisão e preview. Esse procedimento não é adotado para criar a LSE. Os profissionais envolvidos não são legendistas, mas estenotipistas que operam um teclado especial - o estenótipo ligado a uma máquina computadorizada chamada estenógrafo. O estenótipo, equipamento normalmente usado para transcrever pautas de reuniões e assembleias do congresso, de empresas e de sessões de tribunais, está sendo agora usado para legendar programas de TV pré-gravados e ao vivo.

Quando se confecciona a legenda para ouvintes, os parâmetros seguidos pelas companhias de legendagem brasileiras são semelhantes em muitos aspectos àqueles usados na Europa. De acordo com esses parâmetros, as legendas normalmente não têm mais que duas linhas com aproximadamente 145 ou 150 palavras por minuto, com uma permanência na tela de quatro segundos para um total de 64 caracteres. Apesar de não seguir a regra europeia dos seis segundos (D’Ydewalle et al. 1987; Ivarsson \& Carol, 1998; Díaz Cintas \& Remael, 2007; Neves, 2007), o maior número de espaços disponível para quatro segundos, o padrão brasileiro, é muito próximo aos espaços fornecidos por Díaz Cintas e Remael (2007). Maiores velocidades de leitura (160 e 180 palavras por minuto) não são comuns aqui. A tabela 1 apresenta uma proposta de Díaz Cintas e Remael (2007) para mostrar o número de caracteres permitidos para a obtenção de legendas com velocidade de 145 ppm (palavras por minuto):

\begin{tabular}{|l|l|l|l|l|}
\hline & $\begin{array}{l}\text { Segundos: } \\
\text { Quadros }\end{array}$ & Caracteres & $\begin{array}{l}\text { Segundos: } \\
\text { Quadros }\end{array}$ & Caracteres \\
\cline { 2 - 5 } & $01: 00$ & 16 & $02: 00$ & 29 \\
\cline { 2 - 5 } $\begin{array}{l}145 \text { palavras por } \\
\text { minuto }\end{array}$ & $01: 04$ & 17 & $02: 04$ & 32 \\
\cline { 2 - 5 } & $01: 08$ & 18 & $02: 08$ & 34 \\
\cline { 2 - 5 } & $01: 12$ & 20 & $02: 12$ & 36 \\
\cline { 2 - 5 } & $01: 16$ & 23 & $02: 16$ & 38 \\
\cline { 2 - 5 } & $01: 20$ & 25 & $02: 20$ & 40 \\
\cline { 2 - 3 } \\
\cline { 2 - 4 }
\end{tabular}


ARAÚJO \& NASCIMENTO - Investigando parâmetros de legendas...

\begin{tabular}{|l|l|l|l|l|}
\hline $\begin{array}{l}\text { Segundos: } \\
\text { Quadros }\end{array}$ & Caracteres & $\begin{array}{l}\text { Segundos: } \\
\text { Quadros }\end{array}$ & Caracteres & \\
\hline $03: 00$ & 44 & $04: 00$ & 58 \\
\hline $03: 04$ & 46 & $04: 04$ & 60 \\
\hline $03: 08$ & 48 & $04: 08$ & 62 \\
\hline $03: 12$ & 50 & $04: 12$ & 64 \\
\hline $03: 16$ & 52 & & & \\
\hline $03: 20$ & 54 & & & \\
\hline
\end{tabular}

Tabela 1: Máximo de espaços para uma velocidade de legenda de 145 palavras por minuto

(Díaz Cintas e Remael, 2007)

Essas legendas também tendem a ser condensadas para que possam ser lidas no tempo disponível (Cf. tabela 1). A condensação permite o sincronismo entre legenda, fala e imagem, o qual é essencial para facilitar a leitura do espectador: eles devem ter tempo suficiente para ler as legendas, ver as imagens, ouvir o áudio e aproveitar o programa confortavelmente. Ideias redundantes e não relevantes são normalmente eliminadas. A marcação, ou seja, a segmentação da fala em legendas, segue os critérios sugeridos por Gottlieb (1994), citando Helene Reid. O primeiro critério é visual: sempre que houver um corte ou movimento de câmera, é conveniente uma nova legenda. $\mathrm{O}$ segundo é o retórico, ou seja, as legendas seguem o fluxo da fala, terminando quando os falantes param para respirar. Finalmente, na falta de cortes e pausas para respirar, o parâmetro gramatical é adotado. Toda legenda deve ser um todo coerente, ou seja, uma unidade semântica deve permanecer na mesma legenda.

A LSE, por outro lado, não segue os parâmetros de legendagem acima mencionados. A maioria das legendas mostradas na TV são transcrições palavra por palavra e não estão em sincronismo com a fala e/ou imagem. Elas aparecem com um atraso de dois segundos. No entanto, mesmo as poucas legendas em sincronismo (filmes e novelas) apresentam alguns problemas. As legendas apresentam média maior que 16 caracteres por segundo; algumas têm três linhas, tendo uma linha frequentemente mais de 32 caracteres. As informações adicionais, ou seja, aquelas que traduzem as informações dependentes do canal auditivo - identificação de caracteres e efeitos sonoros — são exibidas entre colchetes: [Vera]; [Campainha tocando]; [Porta fechando]. Nenhuma das outras formas de sinalizar esses tipos de informação, tais como fonte em negrito, mudança de cor, repetição de sílabas, onomatopeias, dentre outras, são usadas.

As emissoras brasileiras oferecem dois tipos de LSE: roll-up e pop-on. As legendas roll-up são usadas em programas ao vivo que requerem tradução em tempo Tradução em Revista 11, 2011/2, p. 3 
real, tais como programas de entrevista e telejornais. As palavras são digitadas da esquerda para a direita e rolam continuamente de baixo para cima na parte inferior da tela da televisão. As legendas pop-on aparecem e desaparecem da tela, em sincronismo com fala e imagem. Os canais de TV as utilizam para programas pré-gravados (Franco \& Araújo, 2003).

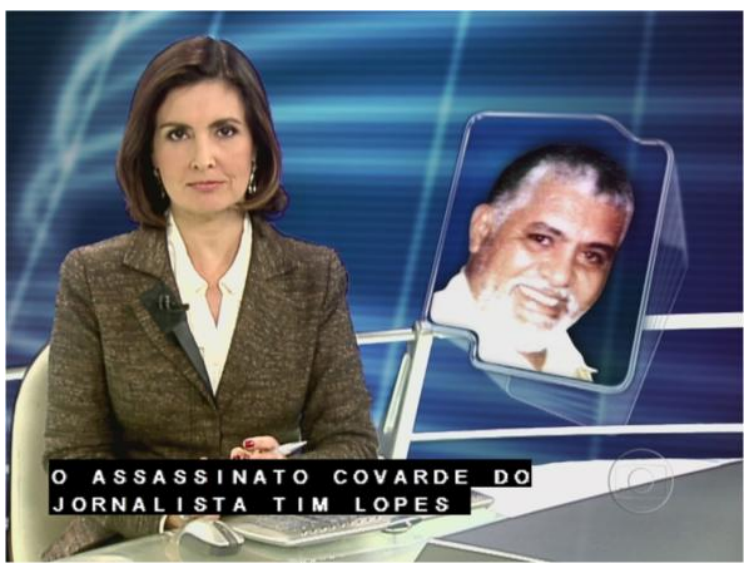

Fig. 01 - Legenda roll-up utilizada em programas ao vivo, como o Jornal Nacional.

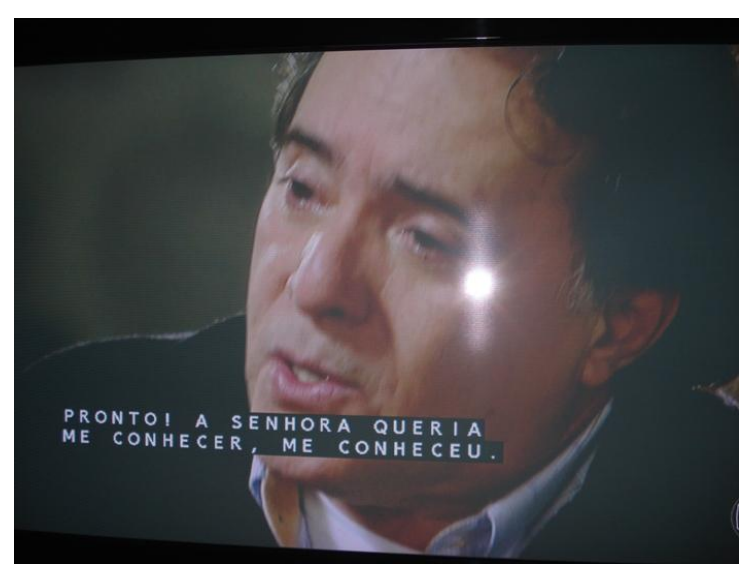

Fig. 02 - Legenda pop-on utilizada em programas pré-gravados, como as novelas

\section{Três estudos em LSE no Brasil}

A Universidade Estadual do Ceará (UECE) vem investigando os parâmetros de LSE que atendem as expectativas da audiência brasileira desde 2002. Três estudos foram realizados até agora. O primeiro analisou a LSE da Rede Globo. À época (2002), 
era a única emissora que exibia programas legendados. Os participantes (15 surdos de nascença do Instituto de Educação para Surdos do Ceará, localizado em Fortaleza, e um grupo controle de 13 estudantes ouvintes) foram expostos a diferentes gêneros de programação. Quatro hipóteses foram formuladas: 1) sempre que a compreensão da fala não dependesse das imagens, a falta de sincronismo entre fala, legenda e imagem não dificultaria a recepção das legendas nem a compreensão de seu conteúdo; 2) sempre que a compreensão dependesse das imagens, a falta de sincronismo entre fala, legenda e imagem dificultaria a recepção; 3) sempre que houvesse sincronismo entre fala, legenda e imagem, a recepção seria facilitada; e 4) sempre que os marcadores orais e acústicos considerados tanto dispensáveis como indispensáveis para o surdo estivessem presentes ou ausentes, a recepção estaria comprometida nos dois casos. (Franco \& Araújo, 2003).

As hipóteses 1, 2 e 4 foram confirmadas, sugerindo que as legendas em sincronismo com fala e imagem facilitariam a recepção dos sujeitos. No entanto, observou-se a rejeição da hipótese 3 , na medida em que talvez apenas o sincronismo entre fala, legenda e imagem e a condensação não seriam suficientes para prover uma recepção eficiente. Os filmes exibidos, apesar de mostrarem fala e imagem sincronizadas e legendas condensadas, também trouxeram dificuldades para os participantes. A explicação possível seria que elas são menos condensadas do que as legendas para ouvintes, já que a edição não seguiu os parâmetros de leitura anteriormente mencionados, e foi realizada apenas em prol do sincronismo entre imagem e legenda (Araújo, 2004a). Como os surdos não entenderam o conteúdo dos filmes, supomos que talvez elas precisassem de um maior grau de condensação para permitir que eles apreciassem o filme como um todo e passassem menos tempo lendo legendas (Franco \& Araújo, 2003). Com esses resultados em mente, decidimos relegendar os mesmos programas para o segundo estudo, utilizando apenas legendas popon e os parâmetros mais comuns seguidos pelas companhias de legendagem no Brasil: 1 segundo $=16$ caracteres $($ Tabela 1$)$.

O segundo estudo testou com o mesmo grupo as legendas condensadas em formato pop-on. Após assistirem aos mesmos programas, os participantes responderam a questionários escritos, compostos de questões abertas e fechadas, uma ferramenta mais eficiente que a usada anteriormente, ou seja, questionários de múltipla escolha, já que os surdos tinham dificuldades em lidar com este tipo de questionário. $\mathrm{O}$ novo 
questionário continha questões sobre "conteúdo", "detalhe" e "imagem" (De Linde \& Kay, 1999) que avaliaram o entendimento do conteúdo e a habilidade de integrar imagens e legendas. Dessa vez, o desempenho dos participantes foi melhor, mas os resultados ainda foram inconclusivos (Araújo, 2004b). Algumas vezes os participantes entenderam o conteúdo, mas não conseguiram falar nada sobre as imagens e os detalhes. Outras vezes, prestavam atenção à imagem e ao conteúdo, mas não conseguiam apontar nenhum detalhe. No tocante à edição, apesar de eles terem sido capazes de assistir ao programa, a quantidade de condensação foi considerada desconfortável (Araújo, 2004a). Por isso, a condensação e a edição foram o foco da terceira pesquisa.

O terceiro estudo (Araújo, 2008) tentou encontrar o nível de condensação usado por companhias de legendagem nacionais que poderia satisfazer as necessidades dos surdos brasileiros. Um grupo de doze surdos composto por estudantes universitários (09) e de ensino médio (03) tiveram encontros mensais com a equipe de pesquisadores por oito meses. Eles assistiram a diferentes vídeos do mesmo programa, com duas LSEs diferentes: a que já existia e a proposta pelos pesquisadores, baseada nos padrões das legendas de ouvintes, além do uso de colchetes para as informações adicionais. Após cada exibição, os participantes eram convidados a falar sobre o conteúdo dos programas e sobre a LSE. Os depoimentos eram dados em LIBRAS e mediados por um intérprete. Os mesmos foram filmados para posterior análise.

Os clipes foram legendados com diferentes velocidades de leitura: um segundo poderia corresponder a 14, 15 e 16 caracteres, o que corresponde às vezes a aproximadamente $145 \mathrm{ppm}$. Eles corroboraram as pressuposições dos surdos do primeiro estudo, que diziam ser possível assistir a programas com o parâmetro de 16 caracteres por segundo, mas ainda demandava muito esforço para ler as legendas, ver as imagens e entender o conteúdo do programa. Isso sugere que mais edição é necessária para que os surdos brasileiros possam entender o conteúdo do programa. Nós não experimentamos uma diferente velocidade de leitura, pois a usada atualmente foi entendida como apropriada pelos participantes.

As sugestões concernentes ao formato, convenções e pontuações são: 1) a cor deve ser amarela em um fundo transparente; 2) a identificação de falantes e os efeitos sonoros devem aparecer entre colchetes; 3) a voz filtrada (voz fora da tela, vinda da televisão, telefone ou rádio, por exemplo) deve estar em itálico; e 4) a linguagem 
utilizada deve ser o português formal. Tentamos introduzir as cores para sinalizar a voz filtrada, a identificação de falantes e efeitos sonoros, mas os surdos acharam o sistema bastante confuso. Eles acharam que era mais fácil lidar com os colchetes. Além das cores, sugerimos outro meio para identificar o falante: colocar a legenda sobre os personagens. Apesar de essa técnica ser vista em alguns filmes legendados, não é comumente utilizada. A maioria dos surdos nunca sequer prestou atenção a isso. Novamente, eles preferiram os colchetes, pois disseram ser melhor a apresentação da legenda centralizada. Duas razões podem ter contribuído para essa rejeição: 1) o hábito — talvez eles tenham recusado as mudanças porque não estão acostumadas a elas; 2) o sistema de cor usado - talvez eles tenham ficado confusos devido ao fato de que foi apresentado um sistema com várias cores diferentes. Talvez, se eles tivessem lidado com um sistema de apenas duas cores diferentes, tal como na versão em português europeu do filme Jesus: a história do Nascimento (Nativity), o resultado poderia ter sido diferente.

Há outro aspecto interessante em relação à identificação de falantes. Os informantes disseram que era muito difícil identificar quem está falando em uma cena. Primeiramente, eles queriam que os personagens fossem nomeados em todas as legendas. Quando argumentamos que muito espaço seria perdido em cada legenda, eles concordaram que a identificação deveria ser apresentada em cada troca de turno da fala. O nosso objetivo é saber se os surdos de outra parte do Brasil concordam com esses pontos de vista.

Expressões da linguagem oral são muito frequentes em diálogos de filmes, já que são simulações de conversações orais. No entanto, essa característica não é reproduzida nos textos das legendas, pois essas são escritas em português formal. Isso pode ser explicado pelo fato de a legenda ser mostrada em língua escrita, o que faz com que os profissionais envolvidos acreditem que devam seguir as mesmas regras da língua escrita. Mas mesmo se os legendistas vissem a situação de forma diferente, seria difícil convencer as distribuidoras e as empresas de legendagem que a linguagem usada para traduzir um filme geralmente deveria ser coloquial (Araújo, 2004b). Essa situação é diferente com a LSE, porque a oralidade é mantida. Quando perguntados se concordavam com esse procedimento, a resposta dos participantes foi negativa. Eles apontaram o aspecto pedagógico da legenda, dizendo que a LSE lhes dá a oportunidade 
de melhorar seus conhecimentos de português. Além disso, eles não se comunicam em linguagem coloquial, então eles não têm que ficar em contato com coloquialismos.

\section{Metodologia}

\subsection{Questões de pesquisa e hipóteses}

A pesquisa busca testar três velocidades de leitura (145, 160 e 180 palavras por minuto) e o modelo europeu de sistema de cor com letras brancas em um fundo preto e as legendas mudando de posição de acordo com o falante. Nossa hipótese é que, como os surdos de Fortaleza, os demais informantes prefiram 145 palavras por minuto como velocidade de leitura e que rejeitem os padrões europeus.

\subsection{Participantes}

Cinquenta participantes pertencentes a dois estados de cada região do Brasil avaliarão as legendas. Os participantes selecionados devem ser falantes de LIBRAS, ter o português como segunda língua, ser surdo de nascença e ter idade entre 18 e 30 anos. 25 participantes já foram testados, 5 em Boa Vista (região norte), 10 em Fortaleza e Salvador (no nordeste) e 10 em Belo Horizonte e Rio de Janeiro (no sudeste). Neste artigo, serão apresentados os resultados da região nordeste, pois foram os únicos já foram analisados.

\subsection{Material}

Quatro curtas-metragens diferentes receberam diferentes parâmetros de legendagem. Três deles testam velocidades de legenda: 1) O amor na sua violência e na sua doçura, 8 minutos. Diretora: Sara Benvenuto - 145 ppm; 2) Reisado Miudim, 13 minutos. Diretor: Petrus Cariry - 160 ppm; 3) Uma vela para Dario, 8 minutos. Diretora: Soraya Ferreira Alves - 180 ppm. O último filme, Águas de Romanza, 10 minutos. Diretoras: Patrícia Baía e Gláucia Soares, foi legendado de acordo com o sistema europeu de LSE e com velocidade de 145 ppm, considerada como ideal pelos consultores surdos.

\subsection{Procedimentos}


O experimento começa com o consentimento do sujeito para participar da pesquisa. Ele assina um documento de acordo com as recomendações do Comitê de Ética da UECE. O documento apresenta os objetivos do estudo, o grupo de pesquisadores e a certeza de que os informantes podem desistir de participar da pesquisa a qualquer momento, mesmo se a decisão é tomada logo após a coleta de dados.

Posteriormente, o participante responde a um questionário pré-coleta, que lhe pede informações pessoais e suas experiências com legendagem. Em seguida, assiste a cada filme individualmente. Depois disso, o participante faz um relato em LIBRAS sobre a trama do filme. O objetivo aqui é saber se ele compreendeu o conteúdo do filme, bem como seus detalhes. Por fim, um questionário pós-coleta sobre os parâmetros é respondido.

Toda a sessão é filmada e mediada por um intérprete. Todas as respostas são traduzidas pelo intérprete e transcritas por um dos membros da equipe. Os protocolos a serem analisados qualitativamente são: 1) questionários pré-coleta; 2) transcrições dos relatos; e 3) questionários pós-coleta.

\section{Resultados}

A análise será apresentada de acordo com a recepção de cada um dos quatro curtas-metragens, já que testam diferentes hipóteses. Os participantes serão nomeados como FOR ou SSA 1, 2, 3, 4 e 5.

\subsection{O amor na sua violência e na sua doçura $\left(O A V D^{2}\right)$}

Esse documentário testa a primeira hipótese: quando a velocidade da legenda é de 145ppm, os surdos conseguem entender o conteúdo do filme, bem como seus detalhes. O filme descreve o trabalho da Delegacia da Mulher. Ele começa apresentando algumas manchetes de jornais e fotografias com cenas de violência contra a mulher. As manchetes são lidas pelo narrador, que não aparece na tela. Posteriormente, a imagem da Delegacia de Polícia é mostrada e uma entrevista com a delegada (Bianca) se inicia (Cf. Figura 03). OAVD também menciona a Lei Maria da Penha, a qual pune praticantes de violência doméstica.

\footnotetext{
${ }^{2}$ Para fins da análise dos dados, a referência aos filmes será feita por meio de suas respectivas siglas, indicadas ao lado de cada nome no título das subseções
}

Tradução em Revista 11, 2011/2, p. 9 
Os participantes de Fortaleza confirmaram a hipótese, pois todos entenderam o conteúdo e conseguiram compreender a maioria dos detalhes. Os detalhes não compreendidos eram sempre os mesmos, sugerindo que a razão para tal ocorrência não era a velocidade de leitura. Quatro deles não perceberam que havia dois falantes no filme. Não conseguiram identificar o narrador, apesar de a legenda [Narrador] aparecer quatro vezes. Uma das razões possíveis para essa incompreensão é que a identificação da delegada não foi legendada, pois já aparecia como informação diegética ${ }^{3}$ no momento em que ela é apresentada ao espectador: "Dra. Bianca Oliveira de Araújo, delegada". É possível que eles tenham ficado confusos, já que nenhum deles foi capaz de dizer o nome dela. No entanto, perceberam que ela era delegada e que a entrevista se passava em uma delegacia.

Os participantes de Salvador também confirmaram a hipótese, mas não conseguiram entender todos os detalhes por uma razão diferente. Três deles foram capazes de identificar o narrador fora de tela, mas não souberam a profissão da mulher e também não perceberam que a entrevista acontecia na delegacia, já que a identificaram como psicóloga ao invés de delegada. Como exemplo, segue o que SSA3 falou sobre isso:

\section{"Tinha uma que tava de frente e outra na lateral. De blusa vermelha que tava no computador lá. Parece ser psicóloga, eu acho. Talvez assistente social, psicóloga".}

De acordo com a nossa análise, não é a velocidade da legenda a responsável pela má recepção. Talvez eles não tenham mencionado esses detalhes por conta de sua falta de conhecimento a respeito da Delegacia da Mulher. No entanto, nossa pressuposição de que a legenda diegética seria suficiente para identificar a delegada foi considerada como ineficiente, já que nenhum dos participantes sabia o nome de Bianca. Se tivéssemos legendado o nome dela da mesma forma que o fizemos com o narrador, esse malentendido provavelmente teria sido evitado.

\footnotetext{
${ }^{3}$ Em cinema e outros produtos audiovisuais, diz-se que algo é diegético quando ocorre dentro da ação narrativa ficcional do próprio filme.
} 


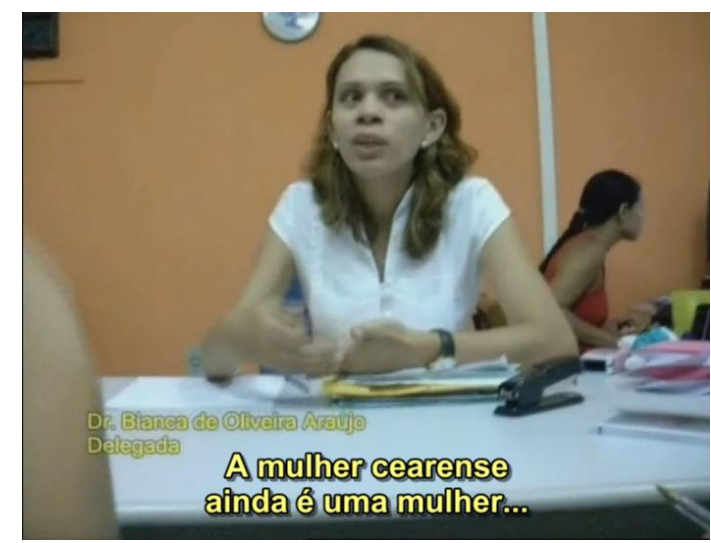

Fig.03- LSE e informação diegética

\subsection{Reisado Miudim (RM)}

Esse filme testa a segunda hipótese: quando a velocidade de legenda é de 160ppm, os surdos conseguem entender o conteúdo do filme, mas não os seus detalhes. O filme conta a história de um menininho, Mateus, e seu avô, que é mestre de um grupo de Reisado. Para se tornar um membro do grupo, Mateus ensaia os passos para ser aprovado pelo avô. O dia finalmente chega. Quando Mateus está pronto para entrar no grupo, seu avô lhe prepara uma surpresa. O velhinho pede a Mateus que vá ao mercado comprar fita e lantejoula. Enquanto isso, prepara um capacete para seu neto usar na sua primeira dança. Outro garoto, Bruno, segue Mateus e tenta fazê-lo comprar um brinquedo (um boneco do Homem-Aranha) ao invés dos itens que o avô pedira. O pedido de Bruno é recusado. RM termina com a estreia de Mateus no Reisado.

Os participantes de Fortaleza refutaram a hipótese. Era esperado que não conseguissem ter uma recepção eficiente, ocasionada pela velocidade da legenda. Contrariando nossas expectativas, quatro participantes entenderam o conteúdo do filme e seus detalhes. Nem mesmo o fato de três dos surdos não conhecerem o Reisado dificultou a compreensão. O relato deles mostrou que assistiram ao filme e puderam aproveitá-lo e aprender um pouco sobre os aspectos da cultura de seu próprio estado. Se as legendas fossem consideradas rápidas, eles não teriam tido tempo de harmonizar legenda, fala e imagem, como os resultados de pesquisas anteriores indicaram. Uma possível explicação para isso é que as legendas seguiram os parâmetros propostos pelos pesquisadores em legendagem: são segmentadas de acordo com os critérios visual, retórico e gramatical e são condensadas de acordo com a velocidade de 160 ppm. 
FOR2 compreendeu a ideia principal, mas não entendeu os detalhes. A surda mencionou que a história era sobre uma dança, um menino e seu avô. Ela disse que as legendas estavam rápidas, mas, a julgar por seu relato, ela não percebeu que sua dificuldade em entender o filme não ocorreu por conta de não conhecer as palavras ou não conseguir ler as legendas, mas, sim, por seu desconhecimento em relação ao Reisado.

\footnotetext{
"Aí depois dançou antes de dormir. Aí calçou o chinelo. $\mathrm{O}$ chinelo foi... Ele vem andando com o chinelo. O vô riu, foi dormir. Aí depois o dia foi chegando..."
}

Apesar da recepção eficiente, os cinco participantes tiveram dificuldades em identificar os sons. O filme não tem uma trilha sonora extra-diegética. Os sons representados são aqueles que aparecem na vida cotidiana dos personagens: máquina de costura, conversas de crianças, água caindo etc. Quatro participantes não relacionaram os sons com os significados que os mesmo tinham dentro do filme. Alguns deles pensaram que a questão dizia respeito apenas à percepção dos sons :
“Ah! Eu senti uma vibração... que tinha um som... eu senti uma vibração muito forte. Eu esqueci de mencionar pra você. Era um som muito forte. Minha cadeira vibrou. O meu peito, sabe? Essa parte do meu corpo aqui vibrou ruidosamente. Em casa, quando assisto TV [sic], eu não me importo com o volume. Então eu não sentia essa vibração. Aqui eu senti. Em casa, eu geralmente tiro o volume da TV. Eu apenas olho a imagem". (FOR1)

Por outro lado, a única que prestou atenção na legendagem dos sons, não percebeu a função deles no filme. Ela apenas notou que eles estavam lá e que poderiam significar algo.

\footnotetext{
"No comecinho tinham (sic) 'murmúrios'. A primeira palavra que apareceu foi murmúrios e depois apareceu algo em inglês, eu não sei. Era isso? Você viu? Na primeira vez apareceu murmúrios e não tinha nada, né?. (FOR3)"
}

Os participantes de Salvador corroboraram os resultados de Fortaleza, já que os dados deles também refutaram a hipótese. Todos foram capazes de assistir ao filme, 
entender o conteúdo e apreender os detalhes. Quanto aos sons, diferentemente dos surdos de Fortaleza, um deles percebeu a relação entre trilha sonora e o enredo do filme. Ele notou que o avô foi até o quarto de Mateus, porque ouviu os passos do neto. Foi a legenda [Arrastar de chinelos] que o levou a chegar a essa conclusão (Figura 04):

\begin{abstract}
"Tinha o avô. Ele parecia ser o instrutor das crianças durante a música. E o menininho queria participar do grupo de dança. Mas ele não podia no momento, mas o seu avô ouviu os passos durante seu ensaio e percebeu que ele queria ser dançarino". (SSA3)
\end{abstract}

SSA3 geralmente assiste a filmes legendados, bem como faz o download de filmes e fansubs da internet (legendas feitas por fãs e disponibilizadas na internet). Provavelmente esta é a razão pela qual foi o único a entender a conexão entre efeito sonoro e a trama do filme.

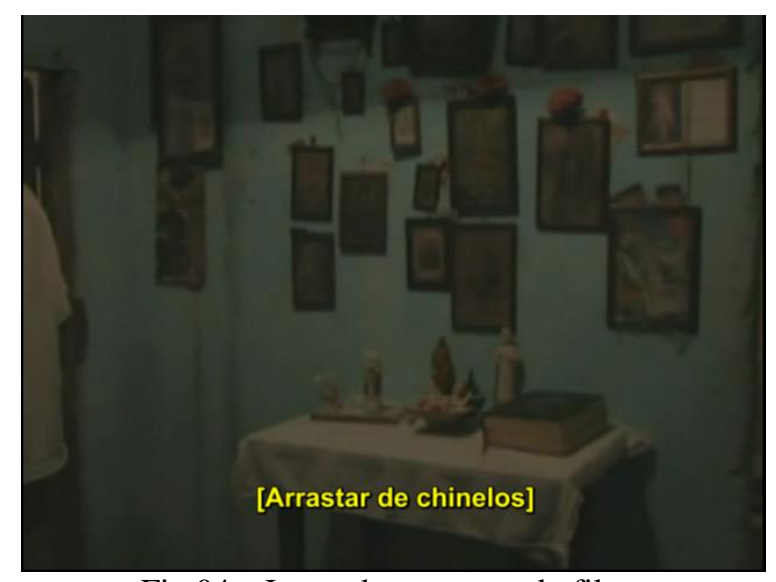

Fig.04 - Legenda para som do filme

\title{
4.3 Uma vela para Dario (UVD)
}

$U V D$ testa a terceira hipótese: quando a velocidade da legenda é de 180ppm, os surdos não conseguem entender o conteúdo do filme e tampouco os detalhes. O filme é uma adaptação do conto homônimo de Dalton Trevisan. Conta a história de um homem que desmaia após atravessar uma avenida movimentada. Muitas pessoas passam por ele e tentam ajudá-lo, mas pouco a pouco desistem de fazê-lo. O homem é abandonado e morre sozinho perto de um depósito de lixo sem os seus pertences pessoais de maior valor. Apenas um menino parece se importar com o morto, pois coloca uma vela acesa 
na mão de Dario. O filme termina com uma voz recitando o poema "Versos Íntimos" de Augusto dos Anjos. O mesmo fala sobre a decomposição do corpo e da solidão da morte.

Contrariando os resultados de estudos anteriores, quatro participantes de Fortaleza foram capazes de assistir a $U V D$ com as legendas rápidas. Os seus relatos e respostas pós-coleta provam que puderam harmonizar legendas e imagens, refutando a hipótese de que o uso da velocidade de legenda de 180ppm dificultaria a recepção dos surdos. Além do mais, apenas um deles reclamou que as legendas estavam rápidas. Apesar de dois participantes desconhecerem o fato de que uma vela sobre um corpo significa que a pessoa está morta, isso não prejudicou a compreensão:

\begin{abstract}
"Então... um homem estava... estava tendo um problema. Ele se sentiu mal e sentou em um banco de praça. Algumas pessoas passaram, mas elas não eram gentis. Eles procuravam pelos objetos, certo? E então tiveram uma ideia. Eles iriam mandá-lo para o hospital de táxi, certo? Aquelas pessoas não se importavam com o homem, né? Na verdade, ele estava todo vestido, de terno e gravata. As pessoas começaram a roubar suas coisas. Eram pessoas mal-educadas”. (FOR1)
\end{abstract}

FOR5 mencionou o episódio da vela, mas achamos que ele apenas inferiu o estado de Dario, já que disse que o homem parecia estar morto:

"Um homem está indo para casa, e então ele passou mal e caiu. Ele parecia estar morto. Algumas pessoas se aproximaram. Eles (sic) tentaram levá-lo para o táxi, mas o taxista perguntou quem pagaria pela corrida. Eles (sic) decidiram tirá-lo do táxi e deixá-lo no chão. As pessoas o deixaram lá. A mulher chamou a polícia, mas a polícia não veio; Eles (sic) olharam os documentos, roubaram seu telefone e o deixaram lá sem nada. Outras pessoas disseram que ele estava bêbado. Duas pessoas sentaram no banco e falaram sobre a situação. Então, um menininho veio e percebeu que algo estava errado. Ele pegou a vela e voltou. A criança percebeu o que estava acontecendo".

Como em $R M$, por conta da falta de conhecimentos de alguns aspectos referentes à cultura dos ouvintes, talvez os participantes não tenham compreendido a ideia de que 
a vela é um símbolo da morte do personagem. No entanto, com base no contexto do filme, eles puderam inferir a informação. Provavelmente a presença da segmentação e da condensação, que garantiram uma boa formatação para o filme, tenha contribuído para que os surdos tivessem uma recepção eficiente mesmo com legendas mais rápidas.

Como os personagens não tinham nome, e eram mencionados na LSE apenas como Homem e Mulher 1, 2, 3 e assim por diante, era esperado que os participantes apresentassem dificuldades em identificar quem falava (Figura 05). Apesar de terem reclamado da rapidez das legendas, eles entenderam a ideia principal do curta: as pessoas morrem sozinhas nas grandes cidades, porque os outros parecem não se importar nem com a vida e nem com a morte de ninguém. A questão do individualismo é chave para o entendimento do enredo. FOR2 disse que as legendas estavam rápidas, já que quatro pessoas falavam ao mesmo tempo. Ela também mencionou que os personagens não tinham nomes:

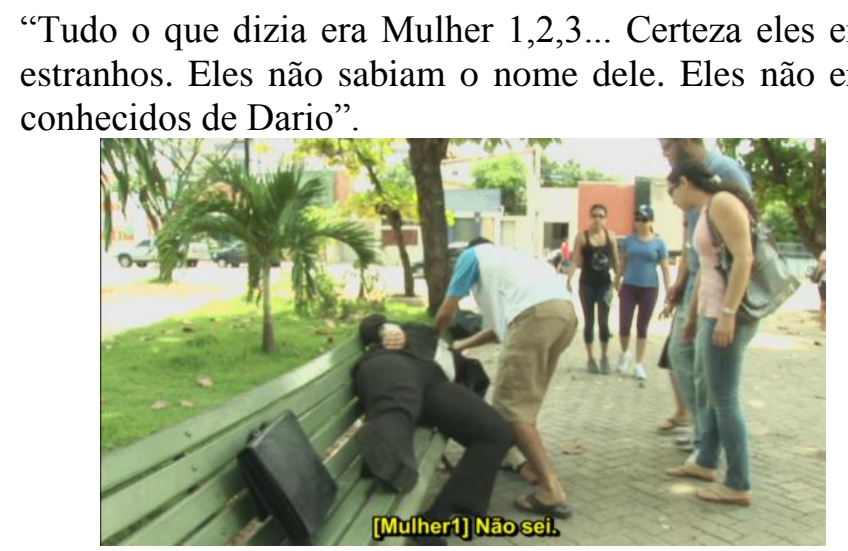

Fig.05 - Identificação de falantes no filme $U V D$

Nenhum surdo de Fortaleza notou a relevância que o efeito sonoro tem para a trama, pois eles não reconheceram os sons traduzidos. O barulho da rua é uma espécie de metáfora, pois representa a desorientação de Dario. O homem se sente mal e cambaleia. A câmera, que opera sob o ponto de vista de Dario, treme até que o homem caia num banco de praça. Apesar de termos repetidamente mostrado essa informação na legenda, nenhum deles entendeu a mensagem. Salvador corroborou os resultados de Fortaleza também refutando a hipótese. Veremos se esses resultados são repetidos em outras regiões do país. No entanto, no que concerne à tradução de informações não verbais, acreditamos que esse tema deva ser objeto de futuras pesquisas. Temos certeza 
de que não haverá dados conclusivos a esse respeito ao final desse estudo, pois se trata de um dado novo no nosso trabalho.

\section{4 Águas de Romanza (AR)}

Esse filme testa o formato europeu de legenda, o qual usa cores para a legendagem de informações não verbais. Com base no terceiro estudo, presumimos que esse sistema não facilitaria a recepção. A trama versa sobre uma menina, Romanza, que vive com sua avó em uma área muito seca no interior do Ceará. Há seis anos, exatamente a idade da menina, não chove lá. Ela pergunta sempre para sua avó quando irá chover. A velha senhora está muito doente e pensa constantemente nas pessoas de sua família que já faleceram (seu marido e a mãe de Romanza). Sentindo que morrerá logo, ela pede a Percival, um caixeiro viajante, que a ajude a levar Romanza para ver a chuva, então eles vão ao Chapadão da Russa, onde há irrigação.

Os dados de Fortaleza refutaram a hipótese. Apesar de a maioria dos participantes ter reclamado das legendas que mudam de posição acompanhando o falante e do uso de cores para sinalizar as informações não verbais, a maioria deles entendeu o conteúdo e uma boa parte dos detalhes. O resultado indica que o uso do sistema europeu não prejudica a recepção.

Três detalhes foram perdidos pelos participantes. Acreditamos, porém, que esse acontecimento não foi causado pelo sistema de legendagem em questão, e sim por problemas na própria legenda. O primeiro problema foi que dois surdos não conseguiram dizer o nome da personagem título. Essa informação foi legendada apenas uma vez e aparece algumas vezes nas falas da avó de Romanza. Pensamos que isso seria suficiente para que os surdos pudessem depreender o nome da menina, um importante aspecto para o entendimento do filme, inclusive do título. No entanto, como é um nome bastante incomum, mesmo para ouvintes, talvez devesse ter sido legendado outras vezes ao longo do filme. 


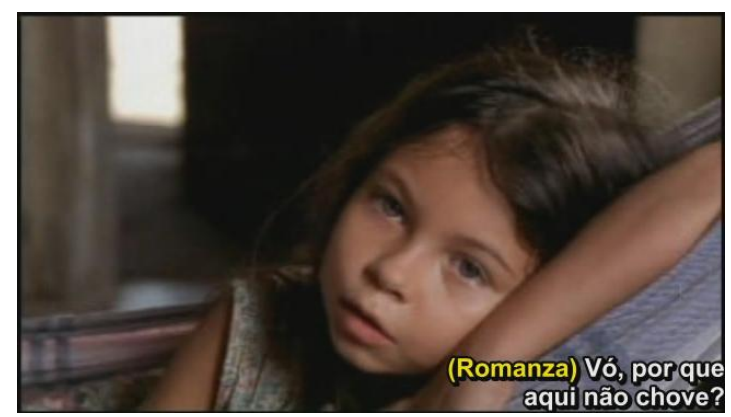

Fig.06 - Sistema Europeu de cores utilizado no filme $A R$

O segundo problema está relacionado com a identificação dos sons. Legendamos todos os sons do filme (o tipo de música, suas letras, sons de animais etc.), mas eles apenas prestaram atenção naqueles diretamente relacionados com o enredo do filme. Eles não notaram [Música Instrumental], mas entenderam que [Música Triste] indicava que o avô de Romanza estava morto e que [Música Alegre] apontava para a felicidade da menina enquanto brincava com as mercadorias do caixeiro viajante.

O último problema de recepção da LSE é final surpreendente do filme, que somente pode ser compreendido se o espectador estiver atento. A cena mostra Romanza vendo pela primeira vez o que ela acredita ser a chuva, mas que na verdade é água vinda de um cano de irrigação. Dois surdos não conseguiram compreender esse detalhe, apesar de seus relatos mostrarem que conseguiram entender a trama. Dessa vez, não consideramos que a LSE seja a causadora da má recepção.

Os resultados de Salvador confirmaram os de Fortaleza: quatro participantes entenderam o conteúdo e quase todos os detalhes. Todos eles identificaram os sons no filme. Apesar da boa recepção, eles reclamaram das cores e das legendas que se deslocam. Três deles entenderam o final do filme.

\section{Considerações Finais}

O primeiro resultado confirmou que a velocidade de legenda de $145 \mathrm{ppm}$ seria o ideal para as necessidades do público surdo. No entanto, os dados também mostraram que 160 e 180 ppm resultaram em uma recepção eficiente no que concerne aos participantes de Salvador e Fortaleza. A pesquisa que será realizada nas outras regiões brasileiras irá confirmar ou rejeitar essa suposição, e então, após mais de nove anos pesquisando esse tema, esperamos chegar a resultados conclusivos, apesar de mais 
pesquisas serem necessárias se queremos encontrar a maneira correta de legendar as informações não-verbais.

\section{Referências bibliográficas}

ARAÚJO, Vera Lúcia Santiago. Closed subtitling in Brazil. In: ORERO, P. (Ed.) Topics in Audiovisual Translation. Amsterdam: John Benjamins, 2004a. p.199212.

ARAÚJO, Vera Lúcia Santiago. To be or not to be natural: Clichés of emotion in screen translation. Meta, v. 49, n.1, 2004b. p. 161-171.

ARAÚJO, Vera Lúcia Santiago. Subtitling for the Deaf and Hard-of-Hearing in Brazil. In: DÍAZ-CINTAS, J.; REMAEL, A.; ORERO, P. (Eds.) Media for All: Subtitling for the Deaf, Audio Description and Sign Language. Kenilworth, Nova Jersey, EUA: Rodopi, 2007. p. 99-107.

ARAÚJO, Vera Lúcia Santiago. Por um modelo de legendagem para surdos no Brasil. Tradução e Comunicação, n. 17, p. 59-76. 2008.

DE LINDE, Zoe.; KAY, Michael. The Semiotics of Subtitling. Manchester: St. Jerome, 1999.

DÍAZ CINTAS, Jorge; REMAEL, Aline. Audiovisual Translation: subtitling. Manchester: St. Jerome, 2007.

D'YDEWALLE, Gerry et al. Reading a message when the same message is available auditorily in another language: the case of subtitling. In: O'Regan, K.K.; LévySchoen, A. (Eds) Eye Movements: From Physiology to Cognition. Amsterdam /New York: Elsevier, 1987. p. 313-321.

FRANCO, Eliana Paes Cardoso; ARAÚJO, Vera Lúcia Santiago. Reading Television Checking Deaf People's Reactions to Closed Subtitling in Fortaleza, Brazil. The Translator, n. 9, v. 2, 2003. p. 249 -267.

GOTTLIEB, Henrik. Subtitling: Diagonal translation. In: DOLLERUP, C.; GOTTliEB, H.; PEDERSEN, V.H. (Eds.) Perspectives: Studies in Translatology. v.2, n.1, 1994. p. 101-121.

IVARSSON, Jan.; CARROL, Mary. Subtitling, Simrishamn, Sweden Grapho-Tryck AB, 1998.

NEVES, Joselia. Vozes que vêem: guia de legendagem para surdos. Leiria, Portugal: Instituto Politéctico de Leiria, 2007. 